STUDI

FRANCESI

\section{Studi Francesi}

Rivista quadrimestrale fondata da Franco Simone

190 (LXIV | I) | 2020

Varia - fasc. I - gennaio-aprile 2020

\title{
MARION LEMAIRE, Robert Macaire: la construction d'un mythe. Du personnage théâtral au type social 1823-1848
}

\section{Michel Arrous}

\section{(2) OpenEdition}

\section{Journals}

Édition électronique

URL : https://journals.openedition.org/studifrancesi/22716

DOI : 10.4000/studifrancesi.22716

ISSN : 2427-5856

Éditeur

Rosenberg \& Sellier

Édition imprimée

Date de publication : 1 avril 2020

Pagination : 177-178

ISSN : 0039-2944

\section{Référence électronique}

Michel Arrous, « MARION LEMAIRE, Robert Macaire: la construction d'un mythe. Du personnage théâtral au type social 1823-1848 », Studi Francesi [En ligne], 190 (LXIV | I) | 2020, mis en ligne le 01 mai 2020, consulté le 03 août 2021. URL : http://journals.openedition.org/studifrancesi/22716 ; DOI : https://doi.org/ 10.4000/studifrancesi.22716

Ce document a été généré automatiquement le 3 août 2021

\section{(c) (i) (9)}

Studi Francesi è distribuita con Licenza Creative Commons Attribuzione - Non commerciale - Non opere derivate 4.0 Internazionale. 


\title{
MARION LEMAIRE, Robert Macaire: la construction d'un mythe. Du personnage théâtral au type social 1823-1848
}

\author{
Michel Arrous
}

\section{RÉFÉRENCE}

MARION LEMAIRE, Robert Macaire: la construction d'un mythe. Du personnage théâtral au type social 1823-1848, Paris, Champion, 2018, 578 pp.

On savait que le bandit de grand chemin était devenu un escroc de la finance, un bonimenteur multicartes, mais il manquait une étude complète de l'impact de ce personnage reparaissant, grotesque et sublime, voire inquiétant, devenu un type social - Barbey d'Aurevilly a vu en lui le symbole d'une époque révolue. Il manquait aussi une étude de cette figure contestataire du pouvoir sous la monarchie de Juillet. Cette double lacune est désormais comblée, grâce à la reconstitution historiographique et à l'analyse du personnage théâtral de Robert Macaire, menées à bien dans la thèse de Marion Lemaire (Paris VIII, septembre 2015). Des investigations nouvelles permettent de comprendre le phénomène Macaire dans ses métamorphoses et, simultanément, le mythe Frédérick Lemaître, lesquels n'avaient jamais fait l'objet d'une étude aussi approfondie.

2 Apparu pour la première fois en 1823 sur la scène de l'Ambigu-Comique dans le mélodrame L'Auberge des Adrets, puis en 1834 dans la pièce Robert Macaire (d'Antier, Alhoy, Saint-Amand et F. Lemaître), ce coquin fascinant s'est profondément inscrit dans l'actualité contemporaine. Ce sont les enjeux de sa représentation et son rôle déterminant dans la formation de l'opinion publique que M. Lemaire définit en suivant minutieusement l'émergence, l'évolution et l'influence de cette figure saisie dans 
toutes ses dimensions et son expansion, au théâtre bien sûr, avec les pratiques scéniques de F. Lemaître, mais aussi dans la gravure satirique et, à un moindre titre, dans le roman. Ce travail de fond sur Robert Macaire et son interprète, qui fut aussi celui de Richard Darlington, de Kean et de Ruy Blas, est organisé selon une perspective d'historiographie théatrale.

Dans la première partie («La formation du couple Lemaître-Macaire», pp. 29-184) l'analyse dramaturgique et philologique, du manuscrit soumis à la censure à la première édition et aux reprises des années 1830, jusqu'à l'édition de 1832 annotée par Lemaitre, on suit les additions, suppressions et modifications de l'intrigue, car L'Auberge des Adrets a connu plusieurs réécritures dues souvent aux interventions et improvisations de l'interprète principal. Des pages denses et passionnantes racontent la naissance, l'évolution du personnage $(1823,1832$ et 1834) et son «amalgame» ou plutôt son appropriation par Frédérick Lemaître.

4 La seconde partie («Quand Macaire échappe à son créateur», pp. 185-331) traite de la puissance de subversion du personnage, plus particulièrement son empreinte dans l'imaginaire collectif, à partir des reprises de L'Auberge des Adrets en 1832. Devenu un type social et politique, Macaire s'émancipe pour incarner désormais l'affairisme et le charlatanisme, et plus encore le capitalisme. Les deux pièces connaissent d'innombrables reprises jusqu'au rétablissement de la censure en 1835 - elles seront à nouveau à l'affiche en mars 1848 -, des suites et des avatars, aussi dans la littérature c'est le cas de Balzac (pp. 246-251) - et des «physiologies». Le personnage bénéficie d'une visibilité renforcée dans la caricature quand Grandville en 1834, Traviès en 1834 et 1839, et Daumier dans ses séries légendées par Philippon de 1837 à 1839, macairisent Louis-Philippe. Même si «les censeurs traquent Robert Macaire dans les moindres pièces» (p. 306), rien ne peut l'empêcher d'être le véritable héros du peuple et d'entrer dans la légende. La puissance de jeu de Frédérick Lemaître explique l'intérêt porté à ce personnage dont la pérennité ne faiblit jamais de 1823 à 1848 , ni même sous la Troisième République, quand la reprise des deux pièces fit de l'ombre aux théâtres parisiens, sans oublier d'autres éclats du mythe, en 1945, dans Les Enfants du Paradis, en 1985, dans Boulevard du Mélodrame mis en scène par Alfredo Arias, et, en 1998, Frédéric ou le Boulevard du Crime, comédie d'Éric-Emmanuel Schmitt. Le comédien vedette voulut s'émanciper de Robert Macaire, mais l'emprise de ce personnage qui le piégeait était si forte que certains dramaturges - c'est le cas de Hugo quand il entreprend Ruy Blas (pp.318-323) - écrivent en pensant à Frédérick Lemaître et à son interprétation de Robert Macaire. À chaque création d'un nouveau rôle, les journalistes et le public retrouvaient ou voulaient retrouver Robert Macaire...

Grâce, d'une part, à une analyse quasiment exhaustive de sources souvent de première main et inédites et, d'autre part, à la reconstitution de l'interprétation de Frédéric Lemaître qui inventa une nouvelle dramaturgie dont l'apport au théâtre romantique mériterait d'être réévalué (voir dans les annexes les pp. 345-398, 469-520, 524-558), Marion Lemaire a renouvelé l'histoire et la perception d'un personnage protéiforme. En s'attaquant au gouvernement et en brocardant les valeurs de la bourgeoisie, Robert Macaire a longtemps marqué l'imaginaire collectif. 